\title{
A Case of Lymphoma Developing in the Rabbit Cecum
}

\author{
Megumi ISHIKAWA ${ }^{1)}$, Hirofumi MAEDA ${ }^{1)}$, Hirotaka KONDO ${ }^{1)}$, Hisashi SHIBUYA ${ }^{1)}$, Mamoru ONUMA ${ }^{1)}$ and \\ Tsuneo $\mathrm{SATO}^{1) *}$ \\ ${ }^{1)}$ Laboratory of Veterinary Pathology, College of Bioresource Sciences, Nihon University, Kameino 1866, Fujisawa, Kanagawa $252-$ \\ 8510, Japan
}

(Received 4 December 2006/Accepted 20 July 2007)

ABSTRACT. A rare lymphoma that developed in the cecum of a domestic pet rabbit (6 years old, male, crossbred) was examined pathologically. The tumor consisted of proliferating neoplastic lymphoid cells, which were strongly stained with anti-CD79 $\alpha$ monoclonal antibody. Electron microscopy revealed the tumor cells were composed of rough endoplasmic reticula and/or dilated rough endoplasmic reticula filled with moderately electron-dense material. These findings indicated the present case was rare digestive tract lymphoma originated from B-lymphocytic lineage in the cecum.

KEY WORDS: cecum, lymphoma, rabbit.

The domestic rabbit tumors have been known to develop in respiratory system and particularly urogenital system, and the number of reports has been increasing lately [3]. Recent studies have reported that malignant lymphoma is the second most frequently occurring tumor [12] and has a predilection for the hilar and mediastinal lymph nodes, liver, spleen, and kidney in domestic pet rabbits [2, 3, 12]. The prognosis for lymphoma in rabbits is poor, and no specific treatment has yet been established [8]. In this study, we pathologically examined an apparently primary lymphoma of the rabbit cecum, which has been rarely reported.

A 6-year-old, male, crossbred pet rabbit of unknown weight was referred a private animal hospital in the Saitama Prefecture with a chief complaint of appetite loss and a reduction in stool volume. A physical examination revealed a molar root abscess and molar overgrowth. In spite of the treatment, it showed no sign of improvement. Further checkups including hematological examination and ultrasound revealed anemia and an abdominal mass, respectively. With owner's permission of surgery, resection of the mass was attempted. However the rabbit died of heart failure during surgery, therefore the necropsy was performed and removed major organs for histopathological examination.

These tissues were routinely fixed in $10 \%$ neutral buffered formalin and embedded in paraffin. Sections were stained with hematoxylin and eosin (HE) for histological observation. Immunohistochemical staining was performed by the streptavidin-biotin-peroxidase (SAB-PO) method using mouse monoclonal anti-human CD3 antibody (DAKO), mouse monoclonal anti-human CD79 $\alpha$ antibody (DAKO) and mouse monoclonal anti-human BLA36kD antibody (NOVOCASTRA). In addition, a part of the formalin-fixed tissue specimens were re-fixed in $1 \%$ glutaral-

\footnotetext{
* Corresdpondence to: Sato, T., Laboratory of Veterinary Pathology, College of Bioresource Sciences, Nihon University, Kameino 1866, Fujisawa, Kanagawa 252-8510, Japan. e-mail: t-sato@brs.nihon-u.ac.jp
}

dehyde-4\% formalin, post-fixed in 1\% osmium-0.1 M cacodylic acid buffer and embedded in epoxy resin. Ultrathin sections were double-stained with uranyl acetate and lead citrate, and observed under a JEM1010 transmission electron microscope (JEOL, Tokyo).

On gross examination, bowl loops were prominently distended. The oval mass sized in $4.0 \times 7.5 \mathrm{~cm}$ was presented in the end of cecum. The mass showed the blotchy hemorrhages under the serosa (Fig. 1). Its cross-section revealed a grayish-white solid tissue with a central necrosis and hemorrhage. A few mesenteric lymph nodes were enlarged. There was a small white induration of the lung. The spleen was slightly swelling and the cross-section showed small grayish nodules with a diameter of $2 \mathrm{~mm}$. No obvious changes were grossly observed in the other tissues.

Histologically, normal architecture of the cecum was destructed and only the remnant of intestinal glands was present with hemorrhage. The tissue had been replaced by diffusely proliferating lymphoid cells (Fig. 2) which had irregularly apparent cellular boundaries, a scant to moderate

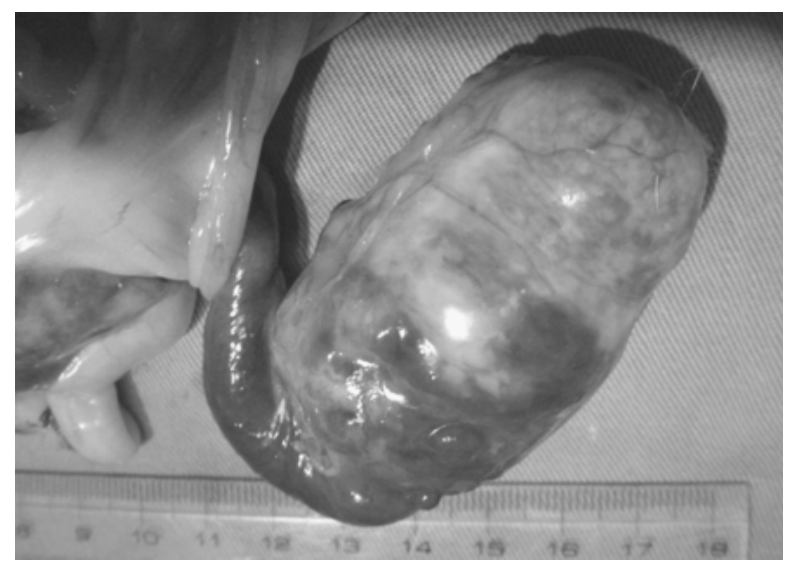

Fig. 1. Gross appearance of the cecal tumor at the surgery. The oval mass was located in the end of cecum. 


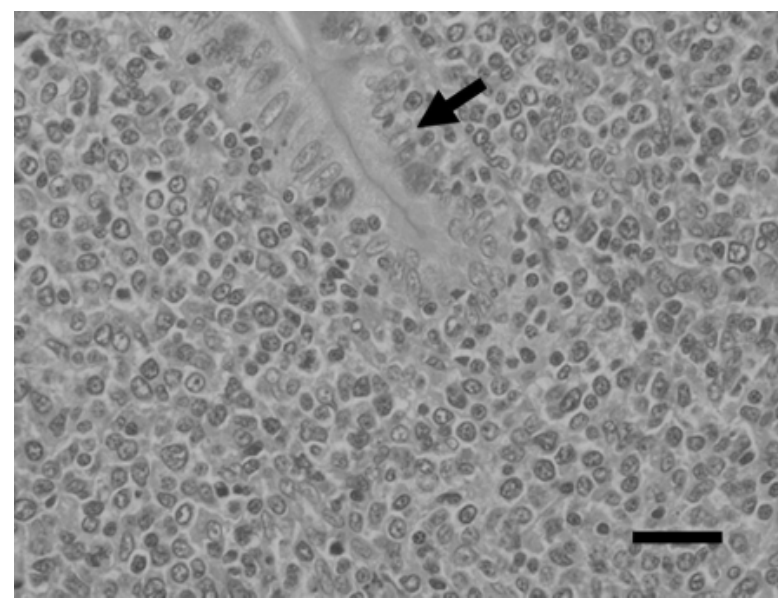

Fig. 2. Histological appearance of the cecal tumor. The neoplastic lymphoid cells proliferated diffusely and destructed the crypt of cecum (arrow). HE stain. Bar $=25 \mu \mathrm{m}$.

amount of cytoplasm, and round to polygonal nuclei with a finely dispersed chromation. The neoplastic cells were approximately 1.5 to 2 red cells in diameter. There were high mitotic rates with a mean of 6 mitoses per $400 \times$ field. The multinucleated giant cells were frequently observed. There were numerous cell debris, phagocytosed by macrophages. There was no evidence of neoplastic penetration into the serosa, however, the lesion adjacent to the serosa showed intensive hemorrhage and edema. In mesenteric lymph nodes, the neoplastic cells diffusely infiltrated and replaced the lymphoid tissue. The architecture of medullary cords was still retained. There were a large area of necrosis, fibrin exudation and hemorrhage. In the spleen, the neoplastic cells were made up of follicular structures and pushed the normal tissue aside. The hemosiderosis was observed in the pressed parenchyma. In the lungs, there was a small lesion of consolidation. Pulmonary alveoli were ruptured with congestion due to emphysema and accompanied by macrophages and multinucleated giant cells. The liver showed infiltration of mature lymphocyte in periphery and perivascular areas with hepatocellular degeneration slightly. It was considered as chronic cholangitis from the morphological point of view in lymphocytes.

Immunohistochemically, many tumor cells were strongly positive for $\mathrm{CD} 79 \alpha$ and partly positive for BLA36kD antibodies (Fig. 3), and most tumor cells were negative for CD3 antibody.

Electron microscopically, the neoplastic cells showed pleomorphism with ovoid to indented nucleoli. They contained frequently prominent nucleoli and moderate amount of heterochromatin. The cytoplasmic organells exhibited a variety of their development. Most cytoplasms had moderate amount of free ribosomes, rough endoplasmic reticula (Fig. 4), and/or dilated rough endoplasmic reticula filled with electron-dense material. The other cells contained poor organelles.

Lymphomas are a diverse group of tumors of reticuloen-

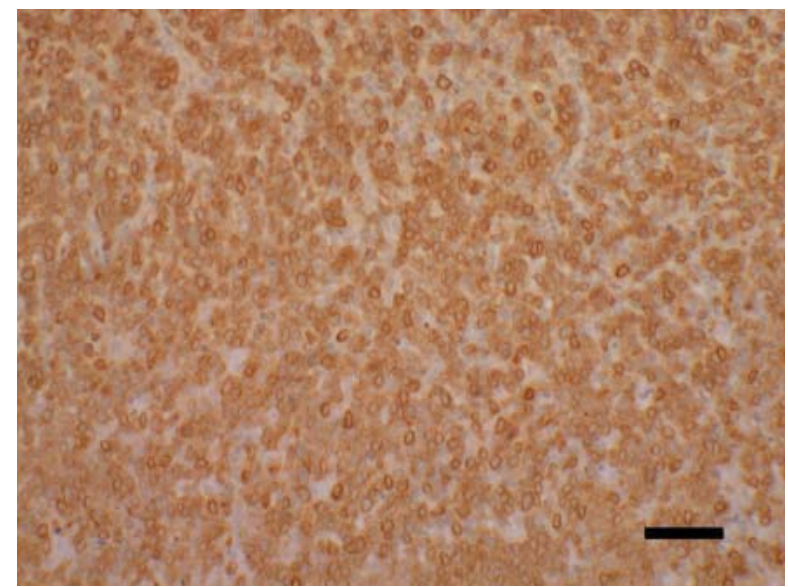

Fig. 3. Cecal tumor. Many tumor cells were positively stained with monoclonal anti-CD79 $\alpha$ antibody. Bar $=50 \mu \mathrm{m}$.

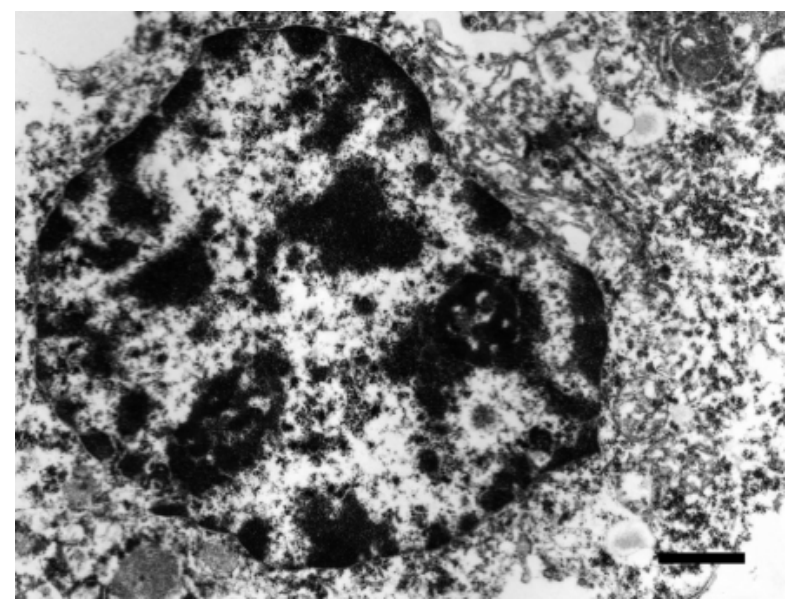

Fig. 4. Electron microscopic appearance of the cecal tumor. Neoplastic cells had ovoid nuclei with prominent nucleoli, rough endoplasmic reticula and free ribosomes. $\mathrm{Bar}=1 \mu \mathrm{m}$.

dothelial origin [13]. They usually originate from lymphoid tissues such as the lymph nodes, spleen, and bone marrow, but may arise in almost all tissues of the body $[12,13]$. The median ages of dogs and cats with lymphoma have been reported to be $6-9$ years and $2-6$ years, respectively $[1,10$, 13]. Six years is an advanced age considering the life expectancy of rabbits. The same reason was suggested that age was a factor in the development of lymphoma in the present case. The paper indicated that most lymphomas in rabbits occur between 8 and 18 months of age [12]. On the other hand, the studies in rabbits have reported that lymphomas including respiratory tract origin frequently occur in young rabbits $[2,3,7,11]$. It is necessary to accumulate the cases for finding the relationship between the development of lymphoma and age.

Lymphomas are anatomically classified into multicentric, thymic, gastrointestinal, and cutaneous. Gastrointestinal lymphomas are very rare in dogs, reportedly accounting for 
$5-7 \%$ of all lymphomas, and they tend to be rare in cats as well $[9,13]$. They have a predilection for the stomach and small intestine [4], presumably because these sites are exposed to physical and chemical stimuli from foods and gastrointestinal secretions for long periods, thereby becoming susceptible to neoplastic transformation. In this case, the lymphoma arose in the rabbit cecum, an intestinal site which performs a very important function. The cecum is far more developed in the rabbit than in other small animals, receives fibrous material from the small intestine, retains it for a long time, and ferments and digests it to absorb energy and produce cecal feces [6]. Thus, the rabbit cecum is most susceptible to physical and chemical stimuli, and is predisposed to developing primary tumors, like the stomach and small intestine of dogs and cats. In rabbits, several cases have been described the evidence of the multiple visceral involvement including intestinal tissue with lymphoma [3, $7,11,12]$. However, no studies have reported primary cecal tumor. As far as author's knowledge, this case is the first report of lymphoma originated from the cecum of rabbit.

Like feline lymphoma, virus particles have been detected in rabbit lymphoma by electron microscopy, and the causeand-effect relationship between virus and lymphoma has attracted attention [5]; however, no virus particles were detected in this case [11].

The present case was immunohistochemically characterized by the presence of scattered cells positively stained with anti-CD3 antibody and by the positive staining of most cells with anti-CD79 $\alpha$ antibody. It was consistent with that reported for the rabbit Harder's gland lymphoma [12]. In addition, the ultrastructural findings revealed the neoplastic lymphoid cells were rich in rough endoplasmic reticula. These results supported the cecal lymphoma was originated from the $\mathrm{B}$ cells. It may be important to elucidate the origin of lymphoma cells in rabbits if the cell type is related with the selection of therapeutic methods and the prediction of prognosis as in dogs and cats.

\section{REFERENCES}

1. Backgren, A. W. 1965. Acta Vet. Scand. (Suppl.) 1: 1-80.

2. Cloyd, G. G. and Johnson, G. R. 1978. Am. Assoc. Lab. Anim. Sci. 28: 66-69.

3. Cooke, S. W., Meredith, A., Deeb, B. and Redrobe, S. 2000, pp. 25-58. In: Manual of Rabbit Medicine and Surgery (Flecknell, P. A. ed.), British Small Animal Veterinary, UK.

4. Gorman, N. T. and White, R. A. S. 1991, pp. 207-263. In: Manual of Small Animal Oncology (Richard, A. S. W. ed.), British Small Animal Veterinary, UK.

5. Gupta, B. N. 1976. Am. J. Vet. Res. 37: 841-843.

6. Harkness, J. E. and Wanger, J. E. 1995, pp. 251-258. In: The Biology and Medicine of rabbits and Rodents, 4th ed, (Harkness, J. E. and Wanger, J. E, eds.), Lippincott Williams \& Wilkins, New York.

7. Hayden, D. W. 1970. Cornell Vet. 60: 73-82.

8. Jenkins, J. V., Deeb, B. J. and Paul-Murphy, J. 1997. pp. 176211. In: Ferrets, Rabbits and Rodents. Clinical Medicine and Surgery, (Hiller, E. V. and Quesenberry, K. E, eds.), W. B. Saunders, New York.

9. Madewell, B. R. and Theilen, G. H. 1987. pp. 392-407. In: Veterinary Cancer Medicine, 2nd ed. (Madewell, B. R. and Thilen, G. H. eds.), Lea and Febiger, Philadelphia.

10. Parodi, A., Wyers, M. and Paris, J. 1968. Bibl. Haematol. 30: 263-267.

11. Shibuya, H., Tajima, M., Kanai, K., Ihara, M. and Nunoya, T. 1999. J. Vet. Med. Sci. 61: 1327-1329.

12. Volopich, S., Gruber, A., Hassan, J., Hittmair, KM., Schwendenwein, I. and Nell, B. 2005. Vet. Ophthalmol. 8: 259-263.

13. Withrow, S. J. and MacEwen, E. G. 1996, pp. 451-494. In: Small Animal Clinical Oncology, 2nd ed. (Withrow, S. J. and MacEwen, E. G. eds.), W.B. Saunders, New York. 